Revista de

Contabilidade e

Organizações

www.rco.usp.br
DOI: http://dx.doi.org/10.11606/rco.v10i28.121505
Journal of

Accounting and

Organizations

\title{
Sofisticação dos investidores, liberdade de movimentação e risco: um estudo do mercado brasileiro de fundos de investimento em ações
}

\author{
Bruno Funchala ${ }^{\text {a }}$ Diogo Lourenço ${ }^{\mathrm{a}}$; Fabio Yoshio Suguri Motoki ${ }^{\mathrm{a}}$
}

${ }^{a}$ Fucape Business School

\section{Informações do Artigo}

Histórico do Artigo

Recebido: 04 de outubro de 2016

Aceito: 13 de dezembro de 2016

Palavras-chave:

Público Alvo.

Fundo de Investimento em Ações.

Comportamento do Gestor.

\begin{abstract}
Resumo
No presente artigo investigamos como a sofisticação dos investidores e o nível de liberdade de entrada e saída do fundo se relacionam com os riscos tomados pelos gestores de fundos de investimento em ações no mercado brasileiro. Os resultados mostram que fundos voltados a investidores sofisticados possuem menor risco, indicando possíveis problemas de agência. Por sua vez, fundos fechados possuem risco aumentado, indicando que gestores podem estar aceitando maior risco em troca de maiores retornos no longo prazo. Usamos informações sobre fundos de ações da base Quantum Axis, totalizando 1.280 fundos entre os anos de 2008 e 2013. Para mitigar preocupações com a adequação da medida de risco, usamos três medidas de risco distintas amplamente adotadas: VaR (Value at Risk), CVaR (Conditional Value at Risk) e Downside Risk.
\end{abstract}

Copyright (C) 2016 FEA-RP/USP. Todos os direitos reservados

\section{INTRODUÇÃO}

Com o desenvolvimento do mercado financeiro, e principalmente com a expansão do mercado de fundos de investimento, entender o comportamento dos gestores é tão importante quanto entender o movimento das diversas classes de ativos que existem na economia. Afinal, fundos de investimento são, hoje, ativos importantes que estão disponíveis na economia para todos os investidores.

Assim, nosso objetivo aqui é estudar como o tipo dos investidores, em termos de sofisticação e o nível de liberdade que possuem em entrar e sair do fundo, se relaciona com os riscos tomados pelos gestores de fundos de investimento em ações no mercado brasileiro. Intuitivamente, gestores de recursos que tem mais liberdade e menor chance de ter seu fundo encerrado possuem incentivos a tomar mais risco, fazendo com que o maior retorno esperado proporcione um melhor resultado em termos de performance, aumentando sua remuneração (CHEVALIER; ELLISON, 1997; QIU, 2003).

A partir de uma base de fundos de investimento em ações, referente ao período de 2008 a 2013 , e um modelo de regressão com dados em painel, correlacionamos o tipo de investidor do fundo com o risco tomado pelo gestor. Os resultados indicam que fundos voltados a investidores sofisticados possuem menor risco. Em particular, fundos voltados a não-residentes, exclusivos do administrador, e para investidores qualificados exibem uma relação negativa estatisticamente significante e economicamente importante, com diminuição de até $74 \%$ do downside risk médio. O limite à liberdade de movimentação, que ocorre em fundos fechados, está associado a um aumento estatisticamente significante e economicamente relevante, de até $42 \%$ do downside risk médio.

O Anuário da Indústria de Fundos de Investimento ANBIMA/FGV 2015 destaca que a indústria de fundos brasileira alcançou mais de R \$2,7 trilhões de patrimônio líquido em 2014, colocando o Brasil entre os sete maiores mercados de fundos do mundo. Apesar disso, a indústria brasileira ainda tem muitos desafios, como a falta de isonomia tributária entre investimentos, a educação do investidor e a internacionalização da indústria (EID JUNIOR; ROCHMAN, 2011).

Autor Correspondente: Tel (27) 40094402

Bruno Funchal agradece ao CNPQ pelo apoio financeiro

E-mail: bfunchal@fucape.br (B. Funchal); di_lourenco@hotmail.com (D. Lourenço); fmotoki@fucape.br (F. Y. S. Motoki)

Fundação Instituto Capixaba de Pesq. em Contabilidade, Economia e Finanças. - Av. Fernando Ferrari, 1358 - Boa Vista - CEP: $29075-505$ - Vitoria, ES - Brasil. 
Varga e Wengert (2011) apontam um maior interesse das pessoas em relação ao mercado financeiro, procurando por melhores retornos, não visando apenas poupança, mas sim investimentos mais rentáveis, além do fato de os fundos de investimento em ações possuírem gestão profissional, maior liquidez no investimento e menor custo de transação. Assim, estudar o comportamento do gestor e suas decisões ganha relevância para os stakeholders do mercado, em especial investidores e reguladores. Entender como o tipo de público-alvo e a liberdade de movimentação relacionam-se com a tomada de riscos pelos gestores pode subsidiar discussões sobre mecanismos de governança para fundos, tema especialmente importante num país com baixa proteção ao investidor como o Brasil (FAN; WEI; XU, 2011; NENOVA, 2003).

Este estudo compreende os fundos da indústria brasileira classificados pela ANBIMA (Associação Brasileira das Entidades dos Mercados Financeiro e de Capitais) como fundos de ações, totalizando 1280 fundos distintos entre os anos de 2008 e 2013. VaR (Value at Risk), CVaR (Conditional Value at Risk) e Downside Risk compõem as medidas de exposição ao risco. Nas próximas seções detalhamos a teoria econômica relevante e a metodologia adotada, e discutimos os resultados encontrados.

\section{REVISÃO DA LITERATURA}

Fundos de investimento compõem um importante setor da economia brasileira. Em 2014, o Brasil contava com 14 mil fundos distintos e 11,5 milhões de cotistas. Estes investimentos alcançaram patrimônio líquido de R \$2,7 trilhões, ou quase 49\% do PIB nominal de 2014 (ANBIMA/FGV; 2015). Apesar da relevância econômica, Matos, Penna e Silva (2015) destacam que a literatura financeira sobre fundos é escassa, e merece estudos mais aprofundados em diversas frentes. Este estudo visa a contribuir com a discussão sobre os determinantes do perfil de risco de fundos de ação.

A literatura brasileira de fundos concentra-se em estudar desempenho e gestão de fundos de investimento. Dalmacio e Nossa (2004) buscam identificar se há relação entre a taxa de administração e a rentabilidade dos fundos. Sob um framework de teoria de agência, a ideia é que quanto maior a remuneração do administrador, maior deve a rentabilidade do fundo. Entretanto, nenhuma relação significante é encontrada. Já Matos e Nave (2012) investigam se há relação entre expertise de gestão e desempenho dos fundos. Os resultados indicam que uma relação estatisticamente significante e positiva, com alto nível de persistência. Matos, Silva e Silva (2015) estudam se gestores de fundos brasileiros possuem habilidade que leve a desempenho superior consistente. $\mathrm{O}$ trabalho aponta que apenas $4 \%$ dos fundos demonstram desempenho superior atribuível à boa gestão, com os demais tendo desempenho superior por pura sorte. Borges e Martelanc (2015) reportam resultados similares a Matos, Silva e Silva (2015), mas que sugerem que uma proporção um pouco maior de fundos exibe retornos superiores por habilidade. Por sua vez, Matos, Penna e Silva (2015) encontram quatro atributos que diferenciam fundos perdedores de vencedores: natureza privada da pessoa jurídica gestora, inventivos associados à cobrança de baixas taxas de administração, taxas de performance, e ênfase nos ganhos compensados pelo risco. Entretanto, a literatura sobre risco de fundos de investimento no Brasil é incipiente.

Chevalier e Ellison (1997) analisam a relação entre a tomada de risco por fundos de investimento e os incentivos de seus gestores. Eles argumentam que as gestoras do fundo costumam receber uma porcentagem fixa do patrimônio administrado, tendo um incentivo a tomar ações que aumentem os ativos sob sua responsabilidade. Esse fato gera um contrato implícito baseado na relação fluxo-performance, que em princípio provê um incentivo aos gestores fundos para que se comportem bem. Desta forma, fundos cujos cotistas sejam menos sensíveis à qualidade da sua gestão tendem a ter menos alinhamento de interesses entre investidores e gestores, uma vez que o enforcement desse contrato implícito é mais fraco. Qiu (2003) encontra que o risco de encerramento do fundo impõe restrições ao comportamento de tomada de risco dos gestores.

Matos, Penna e Silva (2015) encontram que, no Brasil, fundos perdedores e vencedores possuem incentivos dos gestores diferentes, ligados a características dos fundos. Uma implicação no nosso cenário é que fundos com cotistas mais dispersos ou menos sofisticados, ou que imponham mais limites à liberdade de movimentação de seus cotistas, devem enfrentar menos riscos de encerramento, o que aumenta a liberdade do gestor em tomar riscos.

Há evidência de que investidores sofisticados e investidores em geral processam informações de formas diferentes. Frederickson e Miller (2004) conduzem um experimento no qual avaliam como investidores sofisticados (analistas de mercado) e investidores não profissionais avaliam o preço de uma ação quando revelados tanto lucros proforma quanto lucros US-GAAP, com lucros proforma sempre maiores que lucros US-GAAP. 
Os resultados indicam que investidores não sofisticados tendem a atribuir preços maiores para a ação do que investidores sofisticados, que não mudam seu julgamento com o lucro proforma. Menon e Williams (2010) encontram que a reação negativa do mercado quando a firma recebe um parecer de going concern dos auditores é devida principalmente a investidores institucionais, mais sofisticados. Blau, DeLisle e Price (2015) estudam se investidores sofisticados reagem de forma diferente ao tom da conference call de divulgação dos lucros. Seus resultados indicam que investidores sofisticados conseguem interpretar um tom "inflado" na linguagem dos gerentes de forma mais completa que investidores não sofisticados. Huang (2015) provê evidência de que investidores institucionais tendem a corrigir mal apreçamento de ativos e diminuem a volatilidade devida a noise traders.

Wu, Wermers e Zechner (2015) argumentam que os gestores de fundos fechados, dos quais seus cotistas não podem sair até o encerramento, possuem muito mais flexibilidade que seus pares em fundos abertos, já que não precisam se preocupar com os fluxos de entrada e saída do fundo. Da mesma forma que os gestores de fundos fechados podem comprar ativos ilíquidos ou de baixa performance no curto prazo, mas com alta performance esperada no longo prazo, eles podem decidir por investir em ativos mais voláteis, mas de maior retorno esperado.

Tomando esses resultados em conjunto, investidores mais sofisticados parecem realizar melhor julgamento do que investidores não sofisticados. Assim, esse público pode ser mais reativo a riscos considerados desnecessários, levando ao desmonte de suas posições compradas e diminuindo o capital do fundo, consequentemente reduzindo a remuneração do gestor. No limite, a saída de muitos investidores pode inclusive colocar em risco a viabilidade do fundo, fato que é ainda mais grave no caso de fundos exclusivos. Já o fato do fundo impor limites à liberdade de movimentação dos cotistas pode levar os gestores a tomar mais risco, pois eles possuem mais liberdade para escolher ativos com um horizonte de aplicação mais bem definido. Com isso, elaboramos as seguintes hipóteses:

$\mathrm{H}_{1}:$ Fundos destinados a investidores mais sofisticados possuem menor risco.

$\mathrm{H}_{2}$ : Fundos cujos cotistas possuam mais limites à sua saída são mais arriscados

\section{METODOLOGIA}

Obtivemos os dados de fundos de ações brasileiros operando entre 2008 a 2013 da base Quantum Axis. Escolhemos esse período por não ter havido grande mudança no ambiente regulatório, já que a Instrução CVM 409 de 2004, que normatizava o mercado de fundos de investimento, foi substituída pela Instrução CVM 555 em 2014. A amostra efetivamente utilizada foi de 1280 fundos distintos, totalizando 5113 fundos-ano após todas as exigências de dados. A seguir apresentamos as estatísticas descritivas dessa amostra.

\subsection{Medidas de risco}

Operacionalizamos risco, nossa variável dependente, por meio de três medidas: VaR, CVaR e Downside Risk. VaR mede a perda "máxima" aceitável dentro de um horizonte de tempo para um intervalo de confiança qualquer, por exemplo, 95\% ou 99\%. Assim, o VaR médio de $8,44 \%$ encontrado na Tabela 1 quer dizer que num dado mês, com 95\% de confiança, espera-se perder no "máximo" 8,44\% do patrimônio do fundo. Porém, o VaR apresenta deficiências. A perda pode ser maior do que os $8,44 \%$, pois estamos nos apoiando num intervalo de confiança para estimar o "máximo", e o VaR não indica o quanto está em jogo nesse caso (ROCKAFELLAR; URYASEV, 2000). Outro grande problema é que a medida é não-convexa, produzindo um ordenamento de risco não-estável (CHENG; LIU; WANG, 2004).

Uma medida de risco alternativa que ataca esses problemas é o CVaR. O CVaR responde a uma pergunta diferente: dado que a perda ultrapassou o limite do VaR, quanto está em jogo, ou seja, qual é a perda esperada? Desta forma, o CVaR nada mais é do que a média ponderada das perdas para cada evento que exceda o VaR (ROCKAFELLAR; URYASEV, 2000). Assim, o CVaR médio de 6,60\% apresentado na Tabela 1 quer dizer que num dado mês, com $95 \%$ de confiança, caso ocorra um evento mais extremo que o VaR, espera-se perder $6,60 \%$ do patrimônio do fundo. 
A última medida de risco é o Downside Risk (DR), que Sortino e Van der Meer (1991) argumentam ser uma medida superior de risco. O DR mede a distância média dos retornos abaixo de um ponto de corte, o Retorno Mínimo Aceitável (RMA), e por isso também é conhecido por below-target semideviation (SORTINO; VAN DER MEER, 1991). Portanto, o DR é um tipo de semi-variância, e mede somente a parte indesejável do risco, que é o risco para baixo. A equação (i) apresenta a definição formal do DR.

$$
D R=\sqrt{\frac{\sum_{i=1}^{m} \operatorname{Min}\left[0 ;\left(r_{i}-R M A\right)\right]^{2}}{m}}
$$

Em que:

DR: Downside Risk; RMA: Retorno Mínimo Aceitável; r: Retorno; i: Tempo; m: Número de períodos da amostra e Min: Função Mínimo.

A Tabela 1 mostra que a média da amostra é de um DR de 7,54\%. 
Tabela 1. Estatísticas descritivas

\begin{tabular}{|c|c|c|c|c|c|c|c|c|c|}
\hline & Média & DP & Mín & $\mathbf{P 1}$ & $\mathbf{P} 25$ & P50 & P75 & P99 & Máx \\
\hline \multicolumn{10}{|l|}{ Medidas de risco } \\
\hline VaR & 8,4409 & 4,7963 & 0,2956 & 2,3102 & 5,5418 & 7,1247 & 9,3119 & 25,0435 & 60,9997 \\
\hline CVaR & 6,5982 & 5,6319 & $-3,0611$ & $-0,4164$ & 3,5424 & 5,2792 & 7,2452 & 26,9655 & 79,5999 \\
\hline DR & 7,5446 & 6,3450 & 0,0000 & 0,5700 & 4,0200 & 6,1100 & 9,3500 & 29,0500 & 126,2900 \\
\hline \multicolumn{10}{|l|}{ Variáveis de interesse } \\
\hline Investidores sofisticados & 0,5261 & 0,4994 & 0,0000 & 0,0000 & 0,0000 & 1,0000 & 1,0000 & 1,0000 & 1,0000 \\
\hline Investidores não-residentes & 0,0012 & 0,0342 & 0,0000 & 0,0000 & 0,0000 & 0,0000 & 0,0000 & 0,0000 & 1,0000 \\
\hline Exclusivo (genérico) & 0,0311 & 0,1736 & 0,0000 & 0,0000 & 0,0000 & 0,0000 & 0,0000 & 1,0000 & 1,0000 \\
\hline Exclusivo do administrador & 0,0954 & 0,2939 & 0,0000 & 0,0000 & 0,0000 & 0,0000 & 0,0000 & 1,0000 & 1,0000 \\
\hline Exclusivo previdenciário & 0,0008 & 0,0280 & 0,0000 & 0,0000 & 0,0000 & 0,0000 & 0,0000 & 0,0000 & 1,0000 \\
\hline Investidores qualificados & 0,3784 & 0,4850 & 0,0000 & 0,0000 & 0,0000 & 0,0000 & 1,0000 & 1,0000 & 1,0000 \\
\hline Investidores institucionais & 0,0250 & 0,1562 & 0,0000 & 0,0000 & 0,0000 & 0,0000 & 0,0000 & 1,0000 & 1,0000 \\
\hline Investidores private & 0,0176 & 0,1315 & 0,0000 & 0,0000 & 0,0000 & 0,0000 & 0,0000 & 1,0000 & 1,0000 \\
\hline Fundo fechado & 0,1093 & 0,3121 & 0,0000 & 0,0000 & 0,0000 & 0,0000 & 0,0000 & 1,0000 & 1,0000 \\
\hline Carência resgate (dias) & 4,6515 & 38,4216 & 0,0000 & 0,0000 & 0,0000 & 0,0000 & 0,0000 & 61,0000 & 1800,0000 \\
\hline \multicolumn{10}{|l|}{ Características do fundo } \\
\hline Alavancado & 0,3413 & 0,4742 & 0,0000 & 0,0000 & 0,0000 & 0,0000 & 1,0000 & 1,0000 & 1,0000 \\
\hline Tem benchmark & 0,7851 & 0,4108 & 0,0000 & 0,0000 & 1,0000 & 1,0000 & 1,0000 & 1,0000 & 1,0000 \\
\hline Marca d'água (tx perf) & 0,3526 & 0,4778 & 0,0000 & 0,0000 & 0,0000 & 0,0000 & 1,0000 & 1,0000 & 1,0000 \\
\hline Auditoria Big 4 & 0,9711 & 0,1677 & 0,0000 & 0,0000 & 1,0000 & 1,0000 & 1,0000 & 1,0000 & 1,0000 \\
\hline $\ln (\mathrm{PL})$ & 17,1912 & 1,6343 & 10,7470 & 13,4740 & 16,0946 & 17,1445 & 18,3510 & 20,9044 & 22,6338 \\
\hline Captação (\% PL) & $-6,4576$ & 66,1199 & $-514,5200$ & $-317,9403$ & $-20,8825$ & 0,0000 & 17,4955 & 108,0958 & 174,4258 \\
\hline Taxa de administração (\%) & 1,9810 & 1,4229 & 0,0000 & 0,0000 & 1,0000 & 2,0000 & 2,6036 & 6,4824 & 10,5132 \\
\hline Taxa de performance $(\%)$ & 6,6822 & 9,2743 & 0,0000 & 0,0000 & 0,0000 & 0,0000 & 20,0000 & 25,0000 & 50,0000 \\
\hline Idade (anos) em 31/12 & 6,0757 & 5,6267 & 0,2793 & 1,0349 & 2,3847 & 4,2464 & 7,5044 & 27,0062 & 44,2108 \\
\hline Observações & 5113 & & & & & & & & \\
\hline
\end{tabular}

Fonte: Elaborada pelos autores a partir de dados de fundos da base Quantum Axis. 
Notas: A tabela apresenta estatísticas descritivas da amostra, 1280 fundos distintos medidos no mercado brasileiro entre 2008 e 2013. DP é desvio-padrão, Mín é o valor mínimo, P1, P25, P50, P75 e P99 são os percentis 1, 25, 50, 75, e 99, respectivamente. Máx é o valor máximo. VaR é Value at Risk. CVaR é Conditional Value at Risk. DR é Downside Risk. Investidores sofisticados é 1 para fundos destinados a investidores exclusivos, qualificados, institucionais, ou do segmento private. Investidores não-residentes é 1 para fundos destinados a investidores com sede ou domicílio no exterior. Exclusivo (genérico) é 1 para fundos destinados a investidores exclusivos em geral, excluindo os demais tipos de fundos exclusivos. Exclusivo do administrador é 1 para fundos destinados exclusivamente ao administrador. Exclusivo previdenciário é 1 para fundos destinados exclusivamente a um investidor previdenciário. Investidores qualificados é 1 para fundos dedicados a investidores qualificados, excetuando-se os exclusivos. Investidores institucionais é 1 se o fundo for dedicado a investidores institucionais. Investidores private é 1 se o fundo for dedicado a investidores do segmento de private banking. Fundo fechado é 1 se o fundo for do tipo fechado, ou seja, seus cotistas só podem sair do fundo quando do seu encerramento. Alavancado é 1 se o fundo se enquadra na classificação ANBIMA de fundo alavancado. Tem benchmark é 1 se o fundo possui algum tipo de benchmark. Marca d'água é 1 se a política do fundo indicar que a taxa de performance só pode ser cobrada caso o valor da cota exceda o valor da cota quando a última taxa de performance foi cobrada. Auditoria Big 4 é 1 se o fundo tem auditoria externa da Deloitte, Ernst \& Young, KPMG ou PricewaterhouseCoopers. $\ln (\mathrm{PL})$ mede o tamanho do fundo, sendo o logaritmo natural do patrimônio líquido. Captação (\% PL) mede a variação do capital do fundo devido aos fluxos de entrada e saída. Taxa de administração (\%) mede a taxa de administração cobrada pelo gestor. Taxa de performance (\%) mede a taxa de performance cobrada pelo gestor caso o fundo ultrapasse o benchmark. Idade (anos) em 31/12 mede a idade em anos que o fundo possuía em 31/12 do ano da observação.

\subsection{Variáveis de Interesse}

Temos duas classes de variáveis de interesse. A primeira diz respeito ao tipo do investidor a que o fundo se destina (público-alvo). A outra indica se o investidor pode entrar e sair livremente do fundo ou não. O Quadro 1 detalha os tipos da primeira classe. Após o período de estudo, em 2014, a Instrução CVM 555 alterou a instrução anterior que normatizava o mercado até então, a Instrução CVM 409. Todas nossas definições tomam como base esta última, pois era a norma vigente no período.

\begin{tabular}{|c|c|}
\hline Público-alvo & Definição \\
\hline Não-residente & $\begin{array}{l}\text { São pessoas físicas ou jurídicas, inclusive fundos ou outras entidades de investimento } \\
\text { coletivo, com residência, sede ou domicílio no exterior e que investem no Brasil. }\end{array}$ \\
\hline Exclusivo & $\begin{array}{l}\text { Fundo para investidores qualificados constituídos para receber aplicações exclusivamente de } \\
\text { um único cotista. }\end{array}$ \\
\hline Exclusivo do administrador & Mesmas características do Exclusivo, porém destinado somente ao próprio administrador. \\
\hline Exclusivo previdenciário & $\begin{array}{l}\text { Mesmas características do Exclusivo, porém é destinado somente a investimentos em } \\
\text { previdência. }\end{array}$ \\
\hline Qualificado & $\begin{array}{l}\text { Instituições financeiras; companhias seguradoras e sociedades de capitalização; entidades } \\
\text { abertas e fechadas de previdência complementar; pessoas físicas ou jurídicas que possuam } \\
\text { investimentos financeiros em valor superior a } \mathrm{R} \$ 300.000,00 \text { (trezentos mil reais) e } \\
\text { que atestem por escrito sua condição de investidor; fundos de investimento destinados } \\
\text { exclusivamente a investidores qualificados; administradores de carteira e consultores de } \\
\text { valores mobiliários autorizados pela CVM; regimes próprios de previdência social instituídos } \\
\text { pela União, pelos Estados, pelo Distrito Federal ou por Municípios. }\end{array}$ \\
\hline Institucional & $\begin{array}{l}\text { Fundo destinado a instituições financeiras, companhias de seguro e entidades abertas ou } \\
\text { fechadas de previdência complementar, dentre outras instituições, que podem ser investidores } \\
\text { qualificados ou não. }\end{array}$ \\
\hline Private & $\begin{array}{l}\text { Fundo destinado a clientes do segmento de private banking, que podem ser investidores } \\
\text { qualificados ou não. }\end{array}$ \\
\hline Geral & Fundo destinado a qualquer tipo de pessoa, física ou jurídica. \\
\hline
\end{tabular}

Quadro 1. Tipos de público alvo

Fonte: Elaborado pelos autores.

Quanto à segunda classe, a Instrução CVM 409, em seu artigo $5^{\circ}$, divide os fundos em abertos e fechados. Nos fundos fechados, os cotistas só podem resgatar seu investimento ao término do prazo de duração do fundo. Além disso, os fundos podem implementar uma carência de dias para que seja feito um resgate de cotas. 
Definimos investidores sofisticados como os investidores exclusivos, qualificados, institucionais e do segmento private. Assim, a maioria de $61 \%$ dos fundos são destinados a esses investidores. Detalhando os tipos de investidores sofisticados, $3,1 \%$ da amostra são de fundos exclusivos genéricos, ou seja, nem do administrador, nem previdenciário. Estes perfazem $9,5 \%$ e $0,1 \%$ da amostra, respectivamente. Os $37,9 \%$ de fundos destinados a investidores qualificados excluem os fundos exclusivos. Fundos destinados a investidores institucionais e private são relativamente, poucos, perfazendo $2,5 \%$ e $1,8 \%$ da amostra, respectivamente. Em princípio, não fica claro se investidores não-residentes são investidores sofisticados ou não. São um grupo muito pequeno, perfazendo pouco mais de $0,1 \%$ da amostra, e preferimos medir seus efeitos separadamente.

Duas variáveis medem a liberdade que os investidores possuem de sair do fundo. A primeira indica se o fundo é fechado. Aproximadamente $11 \%$ dos fundos são dessa natureza, ou seja, seus investidores só podem resgatar as cotas quando o fundo for encerrado. A outra indica o prazo de carência para o resgate. A média é baixa (4,7 dias), pois menos de $1 / 4$ da amostra impõe algum tipo de carência, que pode chegar a 1800 dias. No caso de ser um prazo variável, por exemplo, que depende do valor resgatado ou da data em que ocorre o resgate, tomamos a média aritmética entre o mínimo e o máximo.

\subsection{Variáveis de controle - características do fundo}

Incluímos uma série de características do fundo para controlar por outras variáveis que podem afetar o risco do fundo. Alavancado é uma dummy que assume o valor 1 se o fundo tem a possibilidade de perder mais do que o seu patrimônio, desconsiderando-se os casos de default nos ativos do fundo, e 0 caso contrário. Essa é a definição dada pela ANBIMA. Fundos assim recorrem a ativos naturalmente mais arriscados, e ser alavancado pode ser um fator determinante do risco do fundo. Pouco mais de 1/3 da amostra é de fundos alavancados.

Tem benchmark é uma dummy que assume valor 1 caso o fundo tenha um benchmark. Brown, Harlow e Starks (1996) afirmam que quando a compensação está ligada à performance, os gestores dos fundos de baixo desempenho podem ter incentivos para manipular os riscos do fundo de forma diferente dos gestores dos fundos de alto desempenho. Basak, Pavlova e Shapiro (2007) demonstram que o risco tomado pelo gestor varia, pois ele monta apostas para bater seu benchmark. A grande maioria de 78,5\% dos fundos possui um benchmark.

Marca d'água (tx perf) é uma dummy que tem valor 1 se o fundo implementa marca d'água. A Instrução CVM 409 não exige marca d'água (ou linha d'água ou high watermark), que especifica que a taxa de performance só pode ser cobrada caso o valor da cota exceda o valor da cota quando a última taxa de performance foi cobrada. Ainda assim, na amostra 35,3\% dos fundos implementam marca d'água, número ligeiramente inferior aos $36 \%$ de fundos que possuem taxa de performance maior do que zero. A marca d'água pode levar os gestores a arriscarem menos, para evitar grandes perdas e se distanciar muito da marca, ou pode levar os gestores a arriscarem mais, para bater a marca e obterem remuneração por performance. Portanto, é uma questão empírica determinar qual dos dois efeitos predomina.

Auditoria Big 4 assume o valor 1 se o fundo é auditado por uma das quatro grandes firmas de auditoria, Deloitte, Ernst \& Young, KPMG e PricewaterhouseCoopers. A evidência da relação entre ser uma firma Big 4 e a auditoria ser de melhor qualidade é contraditória (KHURANA; RAMAN, 2004; LAWRENCE; MINUTI-MEZA; ZHANG, 2011; FRANCIS; YU, 2009; GEIGER; RAMA; 2006). Porém, no pior dos casos ela é uma proxy para características da firma (LAWRENCE; MINUTI-MEZA; ZHANG, 2011). A esmagadora maioria de 97\% dos fundos da amostra é auditada por uma Big 4.

$\mathrm{Ln}(\mathrm{PL})$ é o logaritmo natural do patrimônio líquido do fundo, e representa o estoque de recursos administrado pelo fundo. Já Captação (\% PL) mede a variação do capital do fundo devido aos fluxos de entrada e saída, e pode ser positivo ou negativo, dependendo da direção dos fluxos. Captação foi winsorizada a 1\% (0,5\% em cada cauda) por conta da grande amplitude. Jones $(2007,2009)$ relata que fundos menores e mais jovens exibem maiores retornos, e é razoável argumentar que estes maiores retornos podem estar associados a maiores riscos. Pollet e Wilson (2008) sugerem o mecanismo pelo qual a mudança de tamanho pode influenciar no risco: fundos diversificam suas carteiras em resposta ao crescimento, sugerindo que maior captação pode trazer menos risco. O fundo médio tem tamanho 17,2 (aproximadamente R $\$ 29$ milhões), e diminui seu PL em 6,5\% no período estudado.

Taxa de administração (\%) mede a taxa de administração cobrada pelo gestor. Gil-Bazo e Ruiz-Verdú (2009) encontram uma relação negativa entre taxas de administração e desempenho do fundo, e argumentam que este fato pode estar ligado a problemas de agência. Da mesma forma que afetam o desempenho, esses problemas 
de agência podem ter um impacto negativo nos riscos assumidos pelos fundos. A taxa de administração média na amostra é de aproximadamente $2 \%$.

Taxa de performance (\%) mede a taxa de performance cobrada pelo gestor caso o fundo ultrapasse o benchmark. A intuição é a mesma de Brown, Harlow e Starks (1996) e Basak, Pavlova e Shapiro (2007) para a inclusão da dummy Tem benchmark. Porém, ao invés de indicar se há ou não uma referência, a taxa de performance é uma proxy mais forte para o grau de alinhamento de interesses entre gestor e investidor, ao medir quanto do que exceder o benchmark se torna remuneração do gestor. A média de $6,7 \%$ é relativamente baixa, mas quase $2 / 3$ da amostra não cobra taxa de performance, sendo que ela pode chegar a 50\% do que exceder o benchmark.

Por fim, Idade (anos) em 31/12 mede a idade em anos que o fundo possuía em 31/12 do ano da observação. Jones $(2007,2009)$ relata que fundos mais antigos tendem a produzir menores retornos. Esses retornos mais baixos podem estar ligados a uma gestão mais conservadora, refletindo em menor volatilidade dos retornos. Spiegel e Zhang (2013) demonstram que fundos mais novos exibem uma curva fluxo-retorno diferente de fundos mais antigos. Na média, os fundos da amostra possuem 6,1 anos de idade.

\subsection{O modelo econométrico}

Nosso modelo econométrico relaciona as medidas de risco com as variáveis de interesse e as variáveis de controle que apresentamos. A equação a ser estimada é:

$$
\operatorname{Risco}_{i, t}^{j}=\beta_{0}+\sum_{k=1}^{a} \beta_{k} \cdot \operatorname{VarInt}_{i, t}^{k}+\sum_{l=1}^{b} \gamma_{l} \cdot \text { Controle }_{i, t}^{l}+\epsilon_{i, t}
$$

Em que $\operatorname{Risco}_{i, t}^{j}, j \in\{\mathrm{VaR}, \mathrm{CVaR}, \mathrm{DR}\} \quad$ são as medidas de risco para cada fundo i no ano t, $\operatorname{Var} I n t_{i . t}^{k}$ representa a k-ésima variável de interesse, e Controle $e_{i, t}^{l}$ representa a l-ésima variável de controle, mais um erro $\epsilon_{i, t} \cdot$ No caso, escolhemos deixar o público geral como sendo a referência, sendo seu efeito absorvido pela constante, e testamos duas especificações variando o público-alvo: uma agrupando-os como investidores sofisticados, mais os investidores não-residentes, e outra com todos os tipos separados. Deixamos o público geral na constante pois esse é o grupo que, em tese, traria menor risco para o gestor em termos de encerramento do fundo caso ocorra um resultado negativo, uma vez que o público é pulverizado e não necessariamente sofisticado. Também adicionamos efeitos fixos de ano, e efeitos fixos para cada uma das gestoras com pelo menos 17 fundos, que foi a mediana do número de fundos por firma gestora da amostra. A seguir apresentamos as estimações para as regressões resultantes da Equação (i), usando Mínimos Quadrados Ordinários com dados em painel. Não usamos estimação em painel com efeitos fixos por conta de dummies invariantes no tempo.

\section{RESULTADOS}

A Tabela 2 mostra a estimação da Equação (3.1). As especificações de (1) a (3) usam o agrupamento de investidores sofisticados, enquanto as especificações de (4) a (6) desagregam os investidores sofisticados entre seus tipos.

Os números indicam que o fato do fundo ser destinado a um investidor sofisticado (especificações 1 a 3) traz redução tanto do $\operatorname{VaR}(0,92$ p.p.) quanto do CVaR (0,88 p.p.), sem efeito observável sobre o DR. Em termos relativos, isso equivale a uma redução de 10,9\% do VaR médio, e de 13,4\% do CVaR médio, um efeito não desprezível. Aparentemente, os gestores estão cientes de que estão lidando com investidores capazes de interpretar o ambiente econômico e os ativos selecionados, controlando melhor os riscos desses fundos.

$\mathrm{O}$ efeito do fundo ser destinado a investidores não-residentes é ainda mais pronunciado. Em termos de efeitos sobre os valores médios, temos uma redução de 22,7\% do VaR, 26,1\% do CVaR e de 74,1\% do DR. Quando desagregamos os investidores sofisticados entre seus tipos (especificações 4 a 6 ) o efeito se mantém praticamente inalterado. 
Há também evidência de que fundos exclusivos do administrador possuem menor risco. $\mathrm{O}$ efeito em relação à média da amostra varia entre 13,9\% (VaR) a 26,3\% (DR), considerável e consistente ao longo das três medidas. Fundos destinados a investidores qualificados exibem menor risco nas especificações com VaR e CVaR, 11,3 e 13,0\% respectivamente, consistente com a ideia de que os gestores sabem estar lidando com um público sofisticado. Observamos o mesmo efeito para investidores institucionais e private com o DR, com redução de $25,9 \%$ e $15,9 \%$, respectivamente. Por fim, fundos exclusivos previdenciários estão associados com um decréscimo de $11,6 \%$ do VaR médio.

Tomados em conjunto, esses resultados sinalizam que pode haver problemas de agência na gestão do risco. A maior parte dos tipos de investidores sofisticados exibe alguma redução de risco, sempre de magnitude considerável. Investidores não-residentes também parecem pertencer à classe de investidores sofisticados, o que faz sentido. Esses não-residentes possuem uma burocracia adicional a ser cumprida, aumentando o valor mínimo do investimento para que compense financeiramente, além de se expor a riscos adicionais como a variação cambial.

A flexibilidade que o gestor possui na alocação de ativos só se manifesta no fato do fundo ser fechado. O efeito econômico é de um aumento de aproximadamente 18\% do VaR médio, 24\% do CVaR médio, e 40\% do DR médio. O tempo de carência não exibe nenhuma relação significante.

Tabela 2. Estimativas dos determinantes de risco

\begin{tabular}{|c|c|c|c|c|c|c|}
\hline & $\begin{array}{c}(1) \\
\text { VaR }\end{array}$ & $\begin{array}{c}(2) \\
\text { CVaR }\end{array}$ & $\begin{array}{l}\text { (3) } \\
\text { DR }\end{array}$ & $\begin{array}{c}(4) \\
\text { VaR }\end{array}$ & $\begin{array}{c}\text { (5) } \\
\text { CVaR }\end{array}$ & $\begin{array}{l}\text { (6) } \\
\text { DR }\end{array}$ \\
\hline \multicolumn{7}{|l|}{ Variáveis de interesse: } \\
\hline Investidores sofisticados & $\begin{array}{c}-0,9182 * * * \\
(-3,6253)\end{array}$ & $\begin{array}{c}-0,8817 * * * \\
(-3,4354)\end{array}$ & $\begin{array}{c}-0,1912 \\
(-0,4185)\end{array}$ & & & \\
\hline Investidores não-residentes & $\begin{array}{c}-1,9153 * * * \\
(-3,6268)\end{array}$ & $\begin{array}{c}-1,7202 * * * \\
(-3,3557)\end{array}$ & $\begin{array}{c}-5,5874 * * * \\
(-6,0877)\end{array}$ & $\begin{array}{c}-1,8859 * * * \\
(-3,6015)\end{array}$ & $\begin{array}{c}-1,6560 * * * \\
(-3,2559)\end{array}$ & $\begin{array}{c}-5,5679 * * * \\
(-6,1316)\end{array}$ \\
\hline Exclusivo (genérico) & & & & $\begin{array}{c}0,1796 \\
(0,3550)\end{array}$ & $\begin{array}{c}0,2257 \\
(0,4494)\end{array}$ & $\begin{array}{c}0,4945 \\
(0,4943)\end{array}$ \\
\hline Exclusivo do administrador & & & & $\begin{array}{c}-1,1771 * * * \\
(-4,1195)\end{array}$ & $\begin{array}{c}-1,3078 * * * \\
(-4,8135)\end{array}$ & $\begin{array}{c}-1,9878 * * * \\
(-3,6072)\end{array}$ \\
\hline Exclusivo previdenciário & & & & $\begin{array}{c}-0,9818 * * \\
(-2,2740)\end{array}$ & $\begin{array}{c}-0,5811 \\
(-1,1224)\end{array}$ & $\begin{array}{c}-1,1757 \\
(-1,2453)\end{array}$ \\
\hline Investidores qualificados & & & & $\begin{array}{c}-0,9579 * * * \\
(-3,2774)\end{array}$ & $\begin{array}{c}-0,8565 * * * \\
(-2,8427)\end{array}$ & $\begin{array}{c}0,3628 \\
(0,6929)\end{array}$ \\
\hline Investidores institucionais & & & & $\begin{array}{c}-0,2644 \\
(-0,6716)\end{array}$ & $\begin{array}{c}-0,3407 \\
(-0,8197)\end{array}$ & $\begin{array}{c}-1,9527 * * * \\
(-2,9137)\end{array}$ \\
\hline Investidores private & & & & $\begin{array}{c}-0,3828 \\
(-1,0926)\end{array}$ & $\begin{array}{c}-0,4352 \\
(-1,2615)\end{array}$ & $\begin{array}{l}-1,2027^{*} \\
(-1,8294)\end{array}$ \\
\hline Fundo fechado & $\begin{array}{c}1,5337 * * * \\
(3,1220)\end{array}$ & $\begin{array}{c}1,6030 * * * \\
(2,9448)\end{array}$ & $\begin{array}{c}3,2014 * * * \\
(3,7215)\end{array}$ & $\begin{array}{c}1,5145^{* * *} \\
(3,0700)\end{array}$ & $\begin{array}{c}1,5707 * * * \\
(2,8748)\end{array}$ & $\begin{array}{c}3,0082 * * * \\
(3,4736)\end{array}$ \\
\hline Carência resgate (dias) & $\begin{array}{c}-0,0018 \\
(-1,1177)\end{array}$ & $\begin{array}{c}-0,0017 \\
(-0,9547)\end{array}$ & $\begin{array}{c}-0,0022 \\
(-1,0965)\end{array}$ & $\begin{array}{c}-0,0018 \\
(-1,1480)\end{array}$ & $\begin{array}{c}-0,0018 \\
(-0,9784)\end{array}$ & $\begin{array}{c}-0,0029 \\
(-1,2802)\end{array}$ \\
\hline Características do fundo: & & & & & & \\
\hline Alavancado & $\begin{array}{c}0,2026 \\
(0,8296)\end{array}$ & $\begin{array}{c}0,1226 \\
(0,4749)\end{array}$ & $\begin{array}{c}0,4565 \\
(1,0514)\end{array}$ & $\begin{array}{c}0,2112 \\
(0,8306)\end{array}$ & $\begin{array}{c}0,1083 \\
(0,4020)\end{array}$ & $\begin{array}{c}0,2140 \\
(0,4740)\end{array}$ \\
\hline Tem benchmark & $\begin{array}{c}-0,4867 * * \\
(-2,1647)\end{array}$ & $\begin{array}{l}-0,3906^{*} \\
(-1,7164)\end{array}$ & $\begin{array}{c}-1,9317 * * * \\
(-5,0300)\end{array}$ & $\begin{array}{c}-0,5033 * * \\
(-2,2491)\end{array}$ & $\begin{array}{l}-0,4180 * \\
(-1,8452)\end{array}$ & $\begin{array}{c}-1,9772 * * * \\
(-5,2307)\end{array}$ \\
\hline Marca d'água (tx perf) & $\begin{array}{c}-1,8056^{* *} \\
(-1,9851)\end{array}$ & $\begin{array}{c}-1,4158 * * \\
(-2,0746)\end{array}$ & $\begin{array}{c}-3,4951 * * * \\
(-2,6594)\end{array}$ & $\begin{array}{c}-1,8819 * * \\
(-2,0873)\end{array}$ & $\begin{array}{c}-1,5351 * * \\
(-2,2727)\end{array}$ & $\begin{array}{c}-3,8510 * * * \\
(-2,9053)\end{array}$ \\
\hline Auditoria Big 4 & $-1,5298^{*}$ & $-1,4594 * *$ & $-2,4944^{*}$ & $-1,5237^{*}$ & $-1,4576^{* *}$ & $-2,4833^{*}$ \\
\hline
\end{tabular}

Tabela 2. Estimativas dos determinantes de risco (continuação) 


\begin{tabular}{|c|c|c|c|c|c|c|}
\hline & $\begin{array}{c}(1) \\
\text { VaR }\end{array}$ & $\begin{array}{c}(2) \\
\text { CVaR }\end{array}$ & $\begin{array}{l}\text { (3) } \\
\text { DR }\end{array}$ & $\begin{array}{c}(4) \\
\text { VaR }\end{array}$ & $\begin{array}{c}\text { (5) } \\
\text { CVaR }\end{array}$ & $\begin{array}{l}(6) \\
\text { DR }\end{array}$ \\
\hline & $(-1,9461)$ & $(-2,1116)$ & $(-1,8004)$ & $(-1,9353)$ & $(-2,1136)$ & $(-1,8150)$ \\
\hline $\ln (\mathrm{PL})$ & $\begin{array}{c}-0,1616^{* *} \\
(-2,5415)\end{array}$ & $\begin{array}{c}-0,1682 * * \\
(-2,5511)\end{array}$ & $\begin{array}{c}-0,0988 \\
(-0,8310)\end{array}$ & $\begin{array}{c}-0,1576^{* *} \\
(-2,4428)\end{array}$ & $\begin{array}{c}-0,1585 * * \\
(-2,3603)\end{array}$ & $\begin{array}{c}-0,0606 \\
(-0,5006)\end{array}$ \\
\hline Captação (\% PL) & & & & $\begin{array}{c}0,0008 \\
(1,0338)\end{array}$ & $\begin{array}{c}-0,0006 \\
(-0,6774)\end{array}$ & $\begin{array}{c}0,0011 \\
(0,6961)\end{array}$ \\
\hline Taxa de administração (\%) & $\begin{array}{c}-0,3614 * * * \\
(-4,9871)\end{array}$ & $\begin{array}{c}-0,2876^{* * *} \\
(-4,1002)\end{array}$ & $\begin{array}{c}-0,1767 \\
(-1,2302)\end{array}$ & $\begin{array}{c}-0,3630 * * * \\
(-4,8247)\end{array}$ & $\begin{array}{c}-0,2977 * * * \\
(-4,1419)\end{array}$ & $\begin{array}{l}-0,2750 * \\
(-1,8031)\end{array}$ \\
\hline Taxa de performance $(\%)$ & $\begin{array}{l}0,0888^{*} \\
(1,6636)\end{array}$ & $\begin{array}{l}0,0691 * \\
(1,6937)\end{array}$ & $\begin{array}{c}0,1905 * * \\
(2,4389)\end{array}$ & $\begin{array}{l}0,0921 * \\
(1,7374)\end{array}$ & $\begin{array}{l}0,0730 * \\
(1,7883)\end{array}$ & $\begin{array}{c}0,1905 * * \\
(2,4180)\end{array}$ \\
\hline Idade (anos) em 31/12 & $\begin{array}{c}0,0152 \\
(0,9079)\end{array}$ & $\begin{array}{l}0,0286^{*} \\
(1,9615)\end{array}$ & $\begin{array}{c}-0,0816^{* *} \\
(-2,3274)\end{array}$ & $\begin{array}{c}0,0161 \\
(0,9470)\end{array}$ & $\begin{array}{l}0,0277^{*} \\
(1,8720)\end{array}$ & $\begin{array}{c}-0,0807 * * \\
(-2,2276)\end{array}$ \\
\hline $\mathrm{R}^{2}$ ajustado & 0,4838 & 0,5932 & 0,1321 & 0,4853 & 0,5944 & 0,1410 \\
\hline
\end{tabular}

Fonte: Elaborada pelos autores a partir de dados de fundos da base Quantum Axis.

Notas: A tabela apresenta estimativas para o modelo MQO pooled com uma constante, dummies de ano, dummies para firmas gestoras com 17 ou mais fundos, e erros-padrão agrupados (clustered) por fundo , N=5113, 1280 fundos distintos medidos no mercado brasileiro entre 2008 e 2013. A variável dependente é Value at Risk (VaR), Conditional Value at Risk (CVaR) ou Downside Risk (DR). As estatísticas t estão entre parênteses. *, ** e *** indicam significância estatística a 10\%, 5\% e 1\%, respectivamente. Investidores sofisticados é 1 para fundos destinados a investidores exclusivos, qualificados, institucionais, ou do segmento private. Investidores não-residentes é 1 para fundos destinados a investidores com sede ou domicílio no exterior. Exclusivo (genérico) é 1 para fundos destinados a investidores exclusivos em geral, excluindo os demais tipos de fundos exclusivos. Exclusivo do administrador é 1 para fundos destinados exclusivamente ao administrador. Exclusivo previdenciário é 1 para fundos destinados exclusivamente a um investidor previdenciário. Investidores qualificados é 1 para fundos dedicados a investidores qualificados, excetuando-se os exclusivos. Investidores institucionais é 1 se o fundo for dedicado a investidores institucionais. Investidores private é 1 se o fundo for dedicado a investidores do segmento de private banking. Fundo fechado é 1 se o fundo for do tipo fechado, ou seja, seus cotistas só podem sair do fundo quando do seu encerramento. Alavancado é 1 se o fundo se enquadra na classificação ANBIMA de fundo alavancado. Tem benchmark é 1 se o fundo possui algum tipo de benchmark para cobrança da taxa de performance. Marca d'água é 1 se a política do fundo indicar que a taxa de performance só pode ser cobrada caso o valor da cota exceda o valor da cota quando a última taxa de performance foi cobrada. Auditoria Big 4 é 1 se o fundo tem auditoria externa da Deloitte, Ernst \& Young, KPMG ou PricewaterhouseCoopers. $\ln (\mathrm{PL})$ mede o tamanho do fundo, sendo o logaritmo natural do PL. Captação (\% PL) mede a variação do capital do fundo devido aos fluxos de entrada e saída. Taxa de administração (\%) mede a taxa de administração cobrada pelo gestor. Taxa de performance (\%) mede a taxa de performance cobrada pelo gestor caso o fundo ultrapasse o benchmark. Idade (anos) em 31/12 mede a idade em anos que o fundo possuía em 31/12 do ano da observação.

\subsection{Controles}

Em termos de controles, o fundo ter benchmark está relacionado a um menor risco, o mesmo efeito observado com a existência de marca d'água. Em conjunto, esses resultados indicam que os gestores controlam mais a volatilidade negativa quanto sua remuneração está em risco, indicando novamente um problema de agência.

Ser auditado por uma das quatro grandes auditorias está relacionado a um menor risco. Isso sinaliza que talvez esses fundos implementem melhores processos de gerenciamento de risco.

Fundos maiores apresentam menor risco, em linha com a literatura (JONES; 2007, 2009; POLLET; WILSON, 2008). Observamos o mesmo padrão para a taxa de administração, indicando que ou os gestores tomam menos risco para evitar saída de capital do fundo, ou que problemas de agência fazem com que os administradores tomem menos risco do que o ótimo, ou ambos (GIL-BAZO; RUIZ-VERDÚ, 2009). A taxa de performance anula parcialmente esse efeito, fazendo com que os gestores tomem mais risco, buscando maior receita.

Por fim, os efeitos para idade do fundo são contraditórios, não ficando clara sua contribuição para o risco. A literatura aponta que o risco diminui com a idade, porém, Jones $(2007,2009)$ observa alguma diferença ao categorizar os fundos em jovens (até 2 anos), meia-idade ( 2 a 4 anos) e antigos (mais de 4 anos). Assim, o efeito marginal de um ano pode ser muito pequeno e sujeito a ruído das medidas, o que explicaria a falta de consistência 
que observamos.

\section{CONCLUSÃO}

Neste estudo encontramos que determinados tipos de investidores sofisticados parecem estar associados a uma diminuição dos riscos dos fundos. Esses resultados sugerem que pode haver problemas de agência que levam os gestores a tomar mais riscos em fundos voltados ao público em geral. Esse resultado vai em linha com Matos, Penna e Silva (2015), cujos resultados indicam existência de relação entre mecanismos de alinhamento de interesses entre gestores e cotistas e desempenho de fundos brasileiros. Nosso trabalho estende este resultado, ligando possíveis problemas de agência com tomada de risco.

Fundos fechados, que impõem a maior restrição possível às movimentações pelos investidores, apresentam maior risco. Isso pode ser resultado de um horizonte de mais longo prazo de investimento e da maior flexibilidade que os administradores possuem na alocação de ativos, ao não ter que se preocupar com fluxos de entrada e saída de cotistas. Até onde sabemos esta é uma medição inédita no mercado brasileiro. Encontramos raríssimas referências a fundos fechados na literatura brasileira. Uma das poucas menções é Varga (2001), que explicitamente retira esta classe de fundos de sua análise.

Em conjunto, esses resultados podem subsidiar discussões para aumentar a governança de fundos, visando à proteção do capital dos investidores. Este estudo também responde a um chamado de Matos e Rocha (2009), que clamam por mais estudos que permitam uma melhor compreensão da relação risco-retorno de fundos de investimento em ações.

As variáveis de controle ou não são significantes ou não fogem do padrão esperado. Destacamos os coeficientes negativos associados à existência da marca d'água, sinalizando que a obrigatoriedade deste instrumento pela Instrução CVM 555, que passou a vigorar em 2014, foi acertada. Aparentemente, fundos que adotam essa política apresentam menor risco, compensando o maior risco criado pela taxa de performance em si.

Está em aberto como outras características dos fundos podem influenciar o risco tomado, como políticas de remuneração dos gestores e performance do fundo year to date em relação ao benchmark. Outra investigação é estudar determinantes da continuidade (ou fechamento) dos fundos no mercado brasileiro.

\section{REFERÊNCIAS}

ANBIMA/FGV. Indústria de Fundos de Investimento - Anuário 2015.

BASAK, S.; PAVLOVA, A.; SHAPIRO, A. Optimal asset allocation and risk shifting in money management. Review of Financial Studies, v. 20, n. 5, p. 1583-1621, 2007.

BITTENCOURT, E. Jr. Identificação de perfis de riscos: Uma abordagem por Markowitz, Condicional Value at Risk, DownsideRisk e medida Omega. Departamento de Física e Matemática Universidade de São Paulo, 2011.

BLAU, B. M.; DELISLE, J. R.; PRICE, S. M. Do sophisticated investors interpret earnings conference call tone differently than investors at large? Evidence from short sales. Journal of Corporate Finance, v. 31, p. 203$219,2015$.

BROWN, K. C.; HARLOW, W. V.; STARKS, L. T. Of tournaments and temptations: An analysis of managerial incentives in the mutual fund industry. The Journal of Finance, v. 51, n. 1, p. 85-110, 1996.

CHEN, J.; HONG, H.; HUANG, M.; KUBIK, J. D. Does fund size erode mutual fund performance? The role of liquidity and organization. The American Economic Review, v. 94, n. 5, p. 1276-1302, 2004.

CHEVAliER, J. A.; ELLISON G. D. Risk Taking by mutual funds as a response to incentives. The Journal of Political Economy, v. 105, n. 6, p. 1167-1200, 1997.

CULlEN, G.; GASBARRO, D.; MONROE, G. S.; ZUMWALT, K. Changes to mutual fund risk: intentional or 
mean reverting? Journal of Banking \& Finance, v. 36, n. 1, p. 112-120, 2011.

DRECHSLER, I. Risk choice under high-water marks. NYU Stern, Finance Departament, 2011.

EID JUNIOR, W.; ROCHMAN, R. Um panorama da indústria. A Mutual Funds Industry Overview, 2011.

; MALAQUIAS, R. F. Fundos multimercados: desempenho, determinantes do desempenho e efeito moderador. Universidade Presbiteriana Mackenzie, 2013.

ELTON, E. J.; GRUBER, M. J.; BLAKE, C. R. Incentive Fees and Mutual Funds. The Journal of Finance, v. 58, p. $779-804,2003$

FAN, J. P.; WEI, K. J.; XU, X. Corporate finance and governance in emerging markets: A selective review and an agenda for future research. Journal of Corporate Finance, v. 17, n. 2, p. 207-214, 2011.

FERREIRA, M. A.; KESWANI, A.; MIGUEL, A. F.; RAMOS, S. B. The Determinants of Mutual Fund Performance: A Cross-Country Study. Review of Finance, v. 17, p. 483-525, 2013.

FINN, L.; SAWICKI, J. Smart money and small fundos. Journal of Business Finance and Accounting, v. 29, p.825-846, 2002.

FRANCIS, J. R.; YU, M. D. Big 4 office size and audit quality. The Accounting Review, v. 84, n. 5, p. 1521-1552, 2009.

FREDERICKSON, J. R.; MILLER, J. S. The effects of pro forma earnings disclosures on analysts' and nonprofessional investors' equity valuation judgments. The Accounting Review, v. 79, n. 3, p. 667-686, 2004.

GEIGER, M. A.; RAMA, D. V. Audit firm size and going-concern reporting accuracy. Accounting Horizons, v. 20, n. 1, p. 1-17, 2006.

GRINBLATT, M.; TITMAN, S. Mutual fund performance: An analysis of quarterly portfolio holdings. Journal of business, v. 62, n. 3, p. 393-416, 1989.

GUERCIO, D. D.; REUTHER J. Mutual fund performance and incentive de generate alpha. NBER Working Paper Series, 2011.

HU, P.; KALE J. R.; PAGANI, M.; SUBRAMANIAN, A. Fund flows, performance, managerial career concerns, and risk-taking. Departament of Finance, Accounting, Risk, Management and Insurance, 2008.

HUANG, E. J. The role of institutional investors and individual investors in financial markets: Evidence from closed-end funds. Review of Financial Economics, v. 26, p. 1-11, 2015.

HUANG, J.; SIALM, C.; ZANGH, H. Risk Shifting and Mutual Fund Performance. Review of Financial Studies, v. 24 , n. 8 , p. $2575-2616,2011$. DOI: $10.1093 / \mathrm{rfs} / \mathrm{hhr} 001$.

IQUIAPAZA, R. A. Performance, captação e foco das famílias de fundos de investimento. Tese (Doutorado em Administração) - Universidade Federal de Minas Gerais - UFMG, Minas Gerais, 2009.

JENSEN, M. The Performance of the Mutual Funds in the Period 1954-64. Journal of Finance, v. 23, n. 2, p. 389-416, may, 1968.

An examination of fund age and size and its impact on hedge fund performance. Journal of Derivatives \& Hedge Funds, v. 12, p. 342-350, 2007.

JONES, M. Update to 'An examination of fund age and size and its impact on hedge fund performance.' Journal of Investing, v. 18, p. 108-114, 2009.

KHURANA, I. K.; RAMAN, K. K. Litigation risk and the financial reporting credibility of Big 4 versus non-Big 4 audits: Evidence from Anglo-American countries. The Accounting Review, v. 79, n. 2, p. 473-495, 2004.

LAWRENCE, A.; MINUTTI-MEZA, M.; ZHANG, P. Can Big 4 versus non-Big 4 differences in audit-quality proxies be attributed to client characteristics?. The Accounting Review, v. 86, n. 1, p. 259-286, 2011.

LIMA, I.S., et al. Fundos de investimentos: aspectos operacionais e contábeis. São Paulo: Atlas, 2004.

LYNCH, A.; MUSTO, D. How Investors Interpret Past Fund Returns. The Journal of Finance, v. 58, n.5, p. 20332059, 2003.

MATOS, P. R. F.; PENNA, C. M.; SILVA, A. B. G. Fundos Mútuos de Investimento em Ações no Brasil: Incentivos, 
Gestão e Convergência. Brazilian Business Review, v. 12, n. 2, p. 115-147, 2015.

MATOS, P. R. F.; ROCHA, J. A. T. Ações e Fundos de Investimento em Ações: Fatores e Risco Comuns? Brazilian Business Review, v. 6, n. 1, p. 22-43, 2009.

MENON, K.; WILLIAMS, D. D. Investor reaction to going concern audit reports. The Accounting Review, v. 85, n. 6, p. 2075-2105, 2010.

NENOVA, T. The value of corporate voting rights and control: A cross-country analysis. Journal of Financial Economics, v. 68, n. 3, p. 325-351, 2003.

OLIVEIRA, E. P. Medidas coerentes de risco. Instituto Nacional de Matemática Pura e Aplicada, Março, 2009.

PETERSEN, A. A Indústria de Hedge Fund no Brasil: Uma Avaliação Preliminar. Atlas, 2007.

PINHEIRO, J.L. Mercado de capitais: Fundamentos e Técnicas. Atlas, 2001.

POLLET, J.; WILSON, M. How does size affect mutual fund behavior? Journal of Finance, v. 63, 2941-2969, 2008.

QIU, J. Termination risk, multiple managers and mutual fund tournaments. European Finance Review, v. 2, p. 161-190, 2003.

QUART, R.K. Do mutual funds perform when it matters most to investors? US mutual fund performance and risk in recessions and expansions. Quarterly Journal of Finance, v.1, n. 3, p. 607-664, 2011.

ROCKAFELLAR, R. T.; URYASEV, S. Optimization of conditional value-at-risk. Journal of Risk, v. 2, p. 21-42, 2000.

SANEMATSU, F. C. Remuneração dos gestores, público alvo e conflitos de interesse em fundos de ações no Brasil. Tese (Doutorado em Economia) - Universidade Federal do Rio de Janeiro - UFRJ, Rio de Janeiro, 2013.

SAWICKI, J.; FINN, F. Smart money and small funds. Journal of Business Finance \& Accounting, v. 29, n. 5-6, p. $825-846,2002$.

SORTINO, F. A.; VAN DER MEER, R. Downside risk. The Journal of Portfolio Management, v. 17, n. 4, p. 27-31, 1991.

SPIEGEL Matthew; ZANGH, Hong. Mutual fund risk and market share adjusted fund flows. Journal of Financial Economics, v. 108, n. 2, p. 506-528, 2012.

VARGA, G. Índice de Sharpe e outros Indicadores de Performance Aplicados a Fundos de Ações Brasileiros. Revista de Administração Contemporânea, v. 5, n. 3, p. 215-245, 2001.

VARGA, G.; WENGERT, M. A indústria de fundos de investimentos no Brasil. -Revista de Economia e Administração, v.10, n.1, p.66-109, jan./mar., 2011.

WU, Y.; WERMERS, R.; ZECHNER, J. Managerial Rents vs. Shareholder Value in Delegated Portfolio Management: The Case of Closed-End Funds (December 3, 2015). Available at SSRN: http://ssrn.com/ abstract=2179125 or http://dx.doi.org/10.2139/ssrn.2179125. 